\title{
Levels of Surfactant Proteins A and D and KL-6 Are Elevated in the Induced Sputum of Chronic Obstructive Pulmonary Disease Patients: A Sequential Sputum Analysis
}

\author{
Nobuhisa Ishikawa ${ }^{a}$ c Noboru Hattori ${ }^{a}$ Sonosuke Tanaka ${ }^{a}$ Yasushi Horimasu ${ }^{a}$ \\ Yoshinori Haruta $^{a}$ Akihito Yokoyama ${ }^{b}$ Nobuoki Kohno ${ }^{a}$ Vuokko L. Kinnulac \\ ${ }^{a}$ Department of Molecular and Internal Medicine, Graduate School of Biomedical Science, Hiroshima University, \\ Hiroshima, and ${ }^{b}$ Department of Hematology and Respiratory Medicine, Kochi University, Nankoku, Japan; \\ 'Department of Medicine, Pulmonary Division, University of Helsinki and Helsinki University Central Hospital, \\ Helsinki, Finland
}

\section{Key Words}

Surfactant protein A $\cdot$ Surfactant protein D $\cdot \mathrm{KL}-6 \cdot$ Induced sputum $\cdot$ Sputum fraction

\begin{abstract}
Background: Recent clinical studies have suggested that serum surfactant protein (SP) A, SP-D and Krebs von den Lungen- 6 (KL-6) are potential biomarkers for interstitial lung diseases. Serum levels of SP-A and SP-D have also been found to be elevated in chronic obstructive pulmonary disease (COPD), but their significance has not been evaluated or compared in induced sputum samples obtained directly from the airways. Objective: A sequential sputum analysis was conducted to assess the value of SP-A, SP-D and KL-6 levels in COPD. Methods: The study material consisted of induced sputum samples from 61 subjects, 28 with COPD and 33 with prolonged cough (cough lasting $>3$ weeks and normal spirometry). Sputum was collected in 3 fractions ( 3 periods of 5 min each). Sputum levels of these proteins were measured, and receiver operating characteristic curve analysis was carried out to evaluate the sensitivity, specificity and area under the curve (AUC) for each fraction. Results: The levels of SP-A, SP-D and KL- 6 were higher in patients with
\end{abstract}

COPD than in those with prolonged cough in each of the fractions. Sputum levels of these proteins correlated inversely with obstruction and positively with ageing, smoking history, sputum macrophages and eosinophils. Sputum fractionation had a relatively minor effect on the levels and AUC of these proteins. Conclusion: Sequential sputum analysis from 3 consecutive fractions indicated a significant difference in the levels of SP-A, SP-D and KL- 6 between COPD and prolonged cough. However, sputum fractionation itself had a relatively minor effect on the levels of these proteins.

Copyright $\odot 2011$ S. Karger AG, Basel

\section{Introduction}

Collection of induced sputum is a nearly noninvasive technique for sampling of the airway secretions in chronic obstructive pulmonary disease (COPD). Induction also helps to achieve an adequate sample from the airways from those patients who are not able to produce sputum spontaneously. We and others have used induced sputum in COPD research to study the inflammatory profile, oxidant markers and potential biomarkers for COPD by both hypothesis-driven and proteomic methodologies

\section{KARGER}

Fax +4161306 1234

E-Mail karger@karger.ch

www.karger.com
C 2011 S. Karger AG, Basel

$0025-7931 / 11 / 0821-0010 \$ 38.00 / 0$

Accessible online at:

www.karger.com/res
Noboru Hattori

Department of Molecular and Internal Medicine

Graduate School of Biomedical Sciences, Hiroshima University

1-2-3 Kasumi, Minami-ku, Hiroshima 734-8551 (Japan)

Tel. +81 82257 5196, E-Mail nhattori@ hiroshima-u.ac.jp 
[1-8]. However, several studies have reported alterations in and problems with the cellular and biochemical compositions of sputum specimens during the induction procedure [9-12]. Very little is known about how inflammatory mediators or potential COPD biomarkers vary in induced sputum during the induction procedure.

Surfactant protein (SP) A, SP-D and Krebs von den Lungen-6 (KL-6) have been widely investigated in the circulating blood. All these proteins have been postulated to represent biomarkers for interstitial lung diseases, especially for idiopathic pulmonary fibrosis, though recent studies have revealed elevation of serum SP-A also in COPD $[13,14]$. However, many results in serum and bronchoalveolar lavage fluid have been controversial $[15,16]$. Recently, we performed a lung tissue proteomic study on subjects with COPD. This proteomic screening indicated that SP-A was elevated in mild to very severe COPD, and the result was confirmed in induced sputum specimens by Western blotting [17]. In addition to SP-A, other studies have shown that in advanced COPD, the serum level of SP-D is negatively associated with the forced expiratory volume in $1 \mathrm{~s}\left(\mathrm{FEV}_{1}\right)$, and its increase over a 3 -month period is associated with worsening of the health status of the patients $[18,19]$. Those studies suggested that SP-D may be useful in identifying individuals who are at increased risk of experiencing exacerbations of COPD [20]. Generally, SP-A, SP-D or KL-6 have been investigated from the circulating blood, but they have not been studied separately in induced sputum supernatants of patients with COPD. No study has evaluated the effect of sputum fractionation on the levels of these proteins in COPD.

The present study was undertaken to (1) assess whether sputum levels of SP-A, SP-D and KL-6 can be used to differentiate subjects with COPD from those with prolonged cough and normal spirometry and (2) identify possible changes in the induced sputum levels of these proteins between sequentially collected sputum specimens.

\section{Materials and Methods}

Subjects

Altogether, 61 subjects were included in the study, 28 of whom had COPD [Global Initiative for Chronic Obstructive Lung Disease (GOLD) stage I-III disease]. The diagnosis of COPD was defined according to the GOLD criteria, i.e. $\mathrm{FEV}_{1} /$ forced vital capacity (FVC) $<70 \%$ and bronchodilatation effect $<12 \%[21,22]$. The medications used in our subjects included short-acting $\beta_{2}$-agonists in all subjects, long-acting $\beta_{2}$-agonists in 6 subjects, inhaled corticosteroids in 7 subjects and anticholinergics in 10 subjects. No subjects were receiving systemic corticosteroid therapy. A further 33 subjects with prolonged cough were included as controls.
Table 1. Characteristics of the subjects

\begin{tabular}{|c|c|c|}
\hline & COPD & Prolonged cough \\
\hline Subjects, n & 28 & 33 \\
\hline Females/males, $\mathrm{n}$ & $2 / 26$ & $25 / 8^{* * *}$ \\
\hline Age, years & $70.4 \pm 2.0$ & $52.6 \pm 2.3^{* * *}$ \\
\hline $\mathrm{BMI}$ & $21.9 \pm 0.6$ & $23.6 \pm 0.6$ \\
\hline \multicolumn{3}{|l|}{ Smoking history } \\
\hline Current/former/never, $\mathrm{n}$ & $10 / 18 / 0$ & $3 / 7 / 23$ \\
\hline Pack-year history & $65.6 \pm 8.9$ & $6.5 \pm 2.3^{* * *}$ \\
\hline \multicolumn{3}{|l|}{ Spirometry } \\
\hline FVC, liters & $3.18 \pm 0.12$ & $3.01 \pm 0.14$ \\
\hline $\mathrm{FEV}_{1}$, liters & $1.72 \pm 0.10$ & $2.43 \pm 0.12^{* * *}$ \\
\hline $\mathrm{FEV}_{1}, \%$ predicted & $72.8 \pm 4.5$ & $104.4 \pm 3.0^{* * *}$ \\
\hline $\mathrm{FEV}_{1}$ to $\mathrm{FVC}$ ratio & $0.55 \pm 0.03$ & $0.81 \pm 0.02^{* * *}$ \\
\hline
\end{tabular}

Data are shown as numbers of patients or means \pm SEM, as appropriate. ${ }^{* * *} \mathrm{p}<0.001$ compared to COPD patients (MannWhitney U test or Fisher's exact test).

The diagnosis of prolonged cough lasting $>3$ weeks was made according to the Japanese cough guidelines [23]. Subjects with prolonged cough had no airway obstruction (postbronchodilator $\mathrm{FEV}_{1} / \mathrm{FVC}>70 \%$ ) and no significant reversibility (less than $12 \%$ reversibility for $\mathrm{FEV}_{1}$ after $400 \mu \mathrm{g}$ of inhaled salbutamol) and did not fulfill asthma criteria. Four had allergic rhinitis and 1 had an atopic history. Prolonged cough resulted from cough-variant asthma-like symptoms in 11 subjects, sinobronchial syndrome in 5 , gastroesophageal reflux disease in 3 and postinfectious cough in 14. The subjects were not allowed to smoke during the $12 \mathrm{~h}$ prior to sputum specimen collection. Symptom-free nonsmokers were excluded since they generally have difficulties to produce a representative sputum specimen. Moreover, in preliminary studies and in the study of Ohlmeier et al. [17], SP-A was not generally detectable in the sputum samples of nonsmokers. The Ethics Committee of the Hiroshima University Hospital approved the study. All patients received information about the trial and provided permission to use the samples. For detailed information, see table 1.

\section{Lung Function Values}

Spirometry ( $\mathrm{FEV}_{1}, \mathrm{FVC}$ and $\mathrm{FEV}_{1}$ to $\mathrm{FVC}$ ratio) was performed for all subjects using a computed spirometer as previously described [24, 25]. The protocol for lung function measurements followed the American Thoracic Society recommendations [26].

\section{Sputum Induction and Processing}

Sputum specimens were obtained from subjects with COPD and prolonged cough at the Hiroshima University Hospital according to the guidelines of the European Respiratory Society's Task Force $[27,28]$. In brief, a sputum induction procedure was conducted using 3-5\% hypertonic saline given at 5-min intervals for a maximum of $15 \mathrm{~min}$ via an ultrasonic nebulizer (NE-U12, Omron Co., Kyoto, Japan) with an output of $3.0 \mathrm{ml} / \mathrm{min}$. The concentration of hypertonic saline was changed during the procedure, starting with $3 \%$ and subsequently increasing up to $5 \%$; the 
Table 2. Characteristics of induced sputum

\begin{tabular}{|c|c|c|c|c|c|c|}
\hline & \multicolumn{3}{|l|}{ COPD } & \multicolumn{3}{|c|}{ Prolonged cough } \\
\hline & $5 \mathrm{~min}$ & $10 \mathrm{~min}$ & $15 \min$ & $5 \mathrm{~min}$ & $10 \mathrm{~min}$ & $15 \mathrm{~min}$ \\
\hline Weight, mg & $2.0 \pm 0.3$ & $3.1 \pm 0.5$ & $3.2 \pm 0.4^{\mathrm{b}}$ & $2.2 \pm 0.4$ & $2.7 \pm 0.4$ & $3.5 \pm 0.6^{c}$ \\
\hline Total cell count, $\times 10^{5}$ cells $/ \mathrm{ml}$ & $26.7 \pm 9.1$ & $32.6 \pm 15.2$ & $49.1 \pm 21.9$ & $12.3 \pm 2.7$ & $15.4 \pm 3.5$ & $16.2 \pm 2.7$ \\
\hline Sputum neutrophils, \% & $87.5 \pm 2.0$ & $79.9 \pm 3.4$ & $74.4 \pm 4.0^{\mathrm{a}}$ & $83.5 \pm 3.5$ & $75.1 \pm 3.5$ & $68.3 \pm 4.4^{\mathrm{c}}$ \\
\hline Sputum macrophages, \% & $7.1 \pm 1.6$ & $14.8 \pm 3.3$ & $19.8 \pm 4.1^{\mathrm{a}}$ & $10.3 \pm 2.3$ & $17.3 \pm 2.6$ & $24.6 \pm 3.8^{\mathrm{c}}$ \\
\hline Sputum lymphocytes, \% & $3.0 \pm 1.0$ & $2.4 \pm 0.9$ & $2.2 \pm 0.8$ & $3.0 \pm 0.7$ & $3.9 \pm 1.1$ & $3.5 \pm 0.8$ \\
\hline Sputum eosinophils, \% & $2.3 \pm 1.0$ & $2.9 \pm 1.3$ & $3.8 \pm 1.4$ & $3.1 \pm 1.9$ & $3.9 \pm 2.2$ & $3.5 \pm 1.9$ \\
\hline Sputum neutrophils, $\times 10^{5} / \mathrm{g}$ & $9.7 \pm 2.9$ & $8.2 \pm 2.8$ & $13.0 \pm 5.2$ & $6.6 \pm 1.5$ & $5.0 \pm 1.4$ & $3.9 \pm 0.7$ \\
\hline Sputum macrophages, $\times 10^{5} / \mathrm{g}$ & $1.1 \pm 0.6$ & $0.9 \pm 3.0$ & $3.0 \pm 1.6$ & $0.6 \pm 0.2$ & $1.5 \pm 0.9$ & $1.1 \pm 0.3$ \\
\hline Sputum lymphocytes, $\times 10^{5} / \mathrm{g}$ & $0.18 \pm 0.06$ & $0.12 \pm 0.04$ & $0.41 \pm 0.27$ & $0.20 \pm 0.07$ & $0.34 \pm 0.16$ & $0.15 \pm 0.03$ \\
\hline Sputum eosinophils, $\times 10^{5} / \mathrm{g}$ & $0.15 \pm 0.03$ & $0.12 \pm 0.04$ & $0.53 \pm 0.40$ & $0.09 \pm 0.03$ & $0.10 \pm 0.05$ & $0.11 \pm 0.04$ \\
\hline
\end{tabular}

Data are shown as means \pm SEM. ${ }^{\mathrm{a}} \mathrm{p}<0.01,{ }^{\mathrm{b}} \mathrm{p}<0.001$ between $5-, 10$ - and 15 -min samples obtained from subjects with COPD (repeated-measures ANOVA). ${ }^{c} \mathrm{p}<0.001$ between $5-, 10$ - and 15 -min samples obtained from subjects with prolonged cough (repeatedmeasures ANOVA).

sputum samples produced after the first, second and third 5-min inhalation periods were processed separately $[29,30]$. All sputum samples were processed immediately after induction. The entire sample was weighed and mixed with an equal volume of $0.1 \%$ dithiothreitol (Sigma-Aldrich, St. Louis, Mo., USA) in phosphatebuffered saline solution. The suspension was centrifuged, and the supernatants were immediately stored at $-80^{\circ} \mathrm{C}$ for later assay. The cell pellets from the sputum centrifugation were resuspended, the suspension was air-dried and stained with Diff Quick (Sysmex, Kobe, Japan) and the viabilities and total numbers of the cells were determined. The percentages of macrophages, neutrophils, lymphocytes and eosinophils were obtained by counting $>200$ nonsquamous cells. Sputum samples containing $>20 \%$ squamous cells and cell viability $<70 \%$ were considered inadequate and excluded from the further analyses. The cell counting was performed by an experienced observer blinded to the clinical characteristics of the subjects.

\section{Measurement of SP-A, SP-D and KL-6 Levels in the Induced} Sputum

Sputum levels of SP-A and SP-D were measured by commercially available EIA/ELISA kits (SP-A test: Kokusai-F kit, Sysmex; SP-D kit: Yamasa EIA kit, Yamasa Co., Chiba, Japan) as described previously [13]. KL-6 levels were measured by sandwich-type electrochemiluminescence immunoassay using a Picolumi 8220 Analyzer (Sanko Junyaku, Tokyo, Japan) as described elsewhere [31]. The detection limits for serum SP-A, SP-D and KL-6 were $1 \mathrm{ng} / \mathrm{ml}, 17.2 \mathrm{ng} / \mathrm{ml}$ and $3 \mathrm{U} / \mathrm{ml}$, respectively.

\section{Statistical Analysis}

Data are presented as means \pm SEM. The data were analyzed with a statistical software package (SPSS for Windows, version 15.0, SPSS Inc., Chicago, Ill., USA), and $\mathrm{p}<0.05$ was considered to indicate a significant difference. The comparison between 5-, 10and 15 -min samples was performed by repeated-measures analysis of variance (ANOVA). Differences between 2 groups were ana- lyzed using the Mann-Whitney U test or Fisher's exact test. Correlations between the variables were calculated by Spearman's rank correlation coefficient. Sputum levels of SP-A, SP-D and KL- 6 were further analyzed for their predictive capability to distinguish patients with COPD from those with prolonged cough according to receiver operating characteristic (ROC) curves.

\section{Results}

\section{Subject Characteristics}

The clinical characteristics of the subjects are shown in table 1 . In the COPD group, there were 13 subjects with stage I, 8 with stage II and 7 with stage III COPD according to the GOLD classification. The total number of subjects in the prolonged cough group was 33. Some characteristics differed significantly between the COPD and prolonged cough groups. Younger age, female gender and nonsmokers were more prevalent in the prolonged cough group than in the COPD group.

\section{Sputum Cells}

The weight and total cell counts of the sputum samples obtained at the 3 induction points, i.e. early ( $5 \mathrm{~min})$, intermediate $(10 \mathrm{~min})$ and late $(15 \mathrm{~min})$, are presented in table 2. During induction, the weight of the sputum specimens in both groups of subjects increased significantly $(\mathrm{p}<0.001$ and $\mathrm{p}<0.001$, by repeated-measures ANOVA). The percentage of neutrophils decreased significantly during induction in the COPD and prolonged cough groups $(\mathrm{p}=0.002$ and $\mathrm{p}<0.001$, respectively), whereas the 

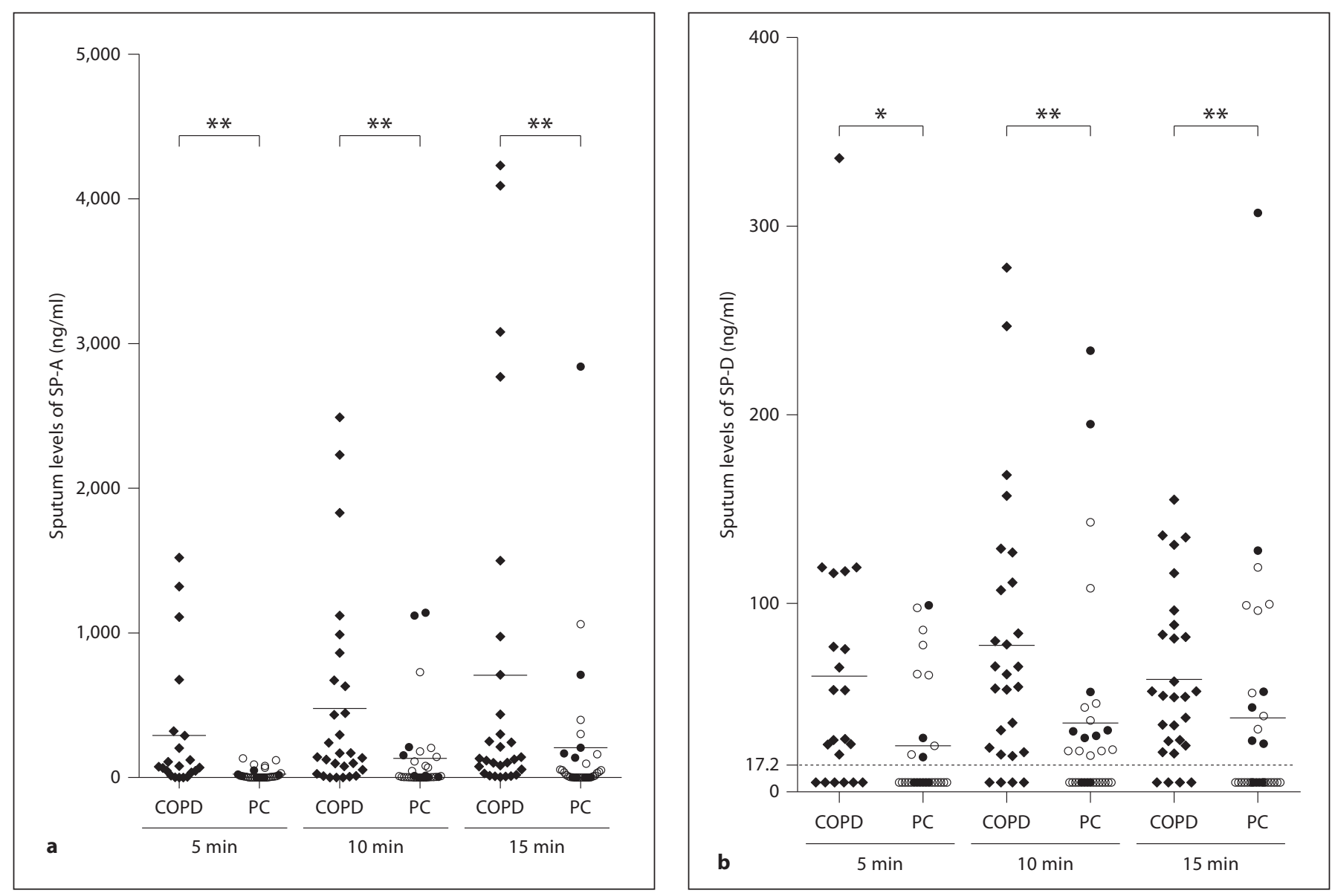

Fig. 1. Sputum levels of SP-A (a), SP-D (b) and KL-6 (c) in 5-, 10- and 15-min induced sputum obtained from 28 subjects with COPD $(-)$ and 33 with prolonged cough (PC). Prolonged cough was related to cough-variant asthma-like symptoms in 11 subjects $(\bullet)$ and to other causes in $22(0) .{ }^{*} \mathrm{p}<0.05,{ }^{* *} \mathrm{p}<0.01,{ }^{* *} \mathrm{p}<0.001$ (Mann-Whitney U test).

percentage of macrophages increased $(\mathrm{p}=0.003$ and $\mathrm{p}<$ 0.001 , respectively). However, no corresponding changes during induction could be seen in the absolute numbers of cells in either group (table 2). When the composition of induced sputum was compared between the subjects with COPD and those with prolonged cough, neither the differential cell count percentages nor absolute cell numbers of the sputum differed between the two groups.

\section{SP-A, SP-D and KL-6 Levels in Induced Sputum}

The levels of SP-A, SP-D and KL- 6 in the different fractions of induced sputum are shown in figure 1. Levels of SP-A, SP-D and KL- 6 did not change during induction in any group (by repeated-measures ANOVA). The levels of SP-A in the 5-, 10- and 15-min sputum fractions were higher in the COPD than in the prolonged cough group $(\mathrm{p}=0.002, \mathrm{p}=0.002$ and $\mathrm{p}=0.005$, respectively, by MannWhitney U test; fig. 1a). The levels of SP-D in each fraction were also higher in the COPD than in the prolonged cough group $(\mathrm{p}=0.014, \mathrm{p}=0.002$ and $\mathrm{p}=0.006$, respectively; fig. 1b). The KL-6 levels remained stable during induction, but were higher in COPD patients compared to prolonged cough patients in all 3 fractions $(p<0.001$, $\mathrm{p}<0.001$ and $\mathrm{p}<0.001$, respectively; fig. $1 \mathrm{c})$.

\section{ROC Curve Analysis}

ROC curve analysis was carried out to evaluate the sensitivity, specificity and diagnostic accuracy of sputum levels of SP-A, SP-D and KL-6 in each fraction. The area under the curve (AUC) was quite similar in each fraction, suggesting that the sputum fractionation had a relatively minor effect on the levels of these proteins (fig. 2). 


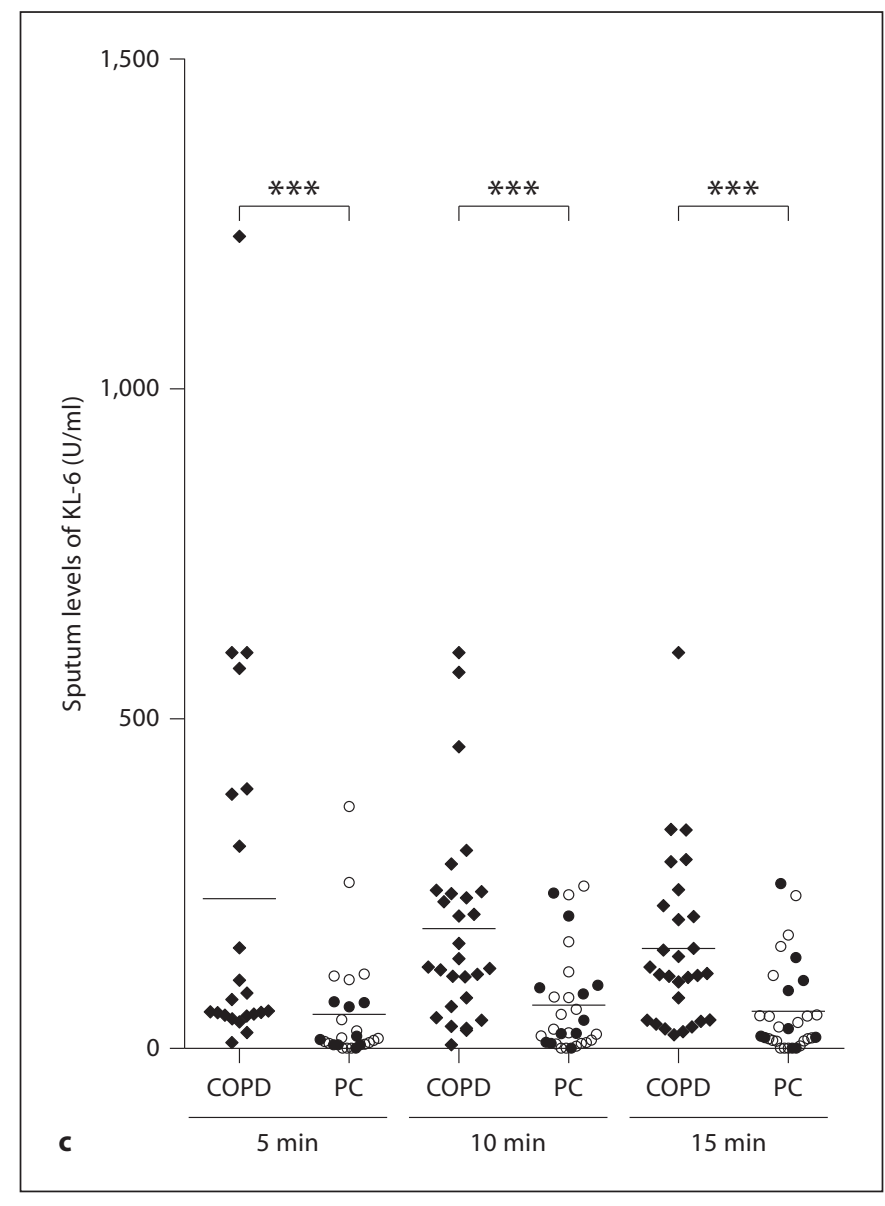

Fig. 1. Sputum levels of KL-6 (c) in 5-, 10- and 15-min induced sputum obtained from 28 subjects with COPD $(\diamond)$ and 33 with prolonged cough (PC). Prolonged cough was related to coughvariant asthma-like symptoms in 11 subjects $(\bullet)$ and to other causes in $22(\bigcirc) .{ }^{* *} \mathrm{p}<0.001$ (Mann-Whitney $U$ test).

Correlation of Sputum Levels of SP-A, SP-D and KL-6 with Clinical Variables, Lung Function Values and Sputum Cell Counts

The levels of SP-A, SP-D and KL-6 correlated positively with age and smoking status and inversely with several lung function values (table 3). The levels of SP-A in the 5-min sputum fraction were higher in males than in females ( $\mathrm{p}=0.011$, Mann-Whitney $\mathrm{U}$ test), and the levels of KL-6 in each fraction were higher in males than in females $(\mathrm{p}=0.009, \mathrm{p}=0.022$ and $\mathrm{p}=0.036$, respectively). Significant correlations were seen between the $\mathrm{FEV}_{1}$ to FVC ratio and induced sputum levels for SP-A in the 5-, 10 - and 15-min fractions $(\mathrm{p}=0.007, \mathrm{p}=0.013$ and $\mathrm{p}=$ 0.020 , respectively, by Spearman's rank correlation coefficient), for SP-D in the 10 -min fraction $(\mathrm{p}=0.010)$ and for KL-6 in each of the 3 fractions $(p=0.002, p=0.003$ and $\mathrm{p}=0.008$, respectively). $\mathrm{FEV}_{1}$ and $\mathrm{FEV}_{1} \%$ predicted also correlated with induced sputum levels of SP-A and KL-6 in the 10-min fraction, whereas they did not correlate with those in the 5-and 15-min fractions. As shown in table 4, the levels of SP-A, SP-D and KL-6 correlated positively with macrophage and eosinophil numbers.

\section{Reproducibility of SP-A, SP-D and KL-6 Analyses}

Sputum levels of SP-A, SP-D and KL- 6 were assayed in two separate runs to validate the reproducibility of the analyses from frozen samples. The two separate runs for SP-A, SP-D and KL- 6 correlated highly significantly ( $\mathrm{r}=$ 0.953 and $\mathrm{p}<0.001, \mathrm{r}=0.948$ and $\mathrm{p}<0.001$, and $\mathrm{r}=0.971$ and $\mathrm{p}<0.001$, respectively, by Spearman's rank correlation coefficient).

\section{Discussion}

The present study supports the hypothesis that the levels of SP-A, SP-D and KL- 6 are elevated in COPD when analyzed from induced sputum specimens. Sputum levels of all these proteins could differentiate subjects with COPD from those with prolonged cough. In particular, the levels of SP-A, SP-D and KL-6 correlated inversely with obstruction and positively with ageing and smoking history. Overall, sputum fractionation had a relatively minor effect on the levels and AUC of these proteins. This is the first sequential sputum study investigating the levels of SP-A, SP-D and KL-6 in patients with COPD.

SP-A and SP-D belong to a subgroup of the C-type lectin superfamily (molecular weight: $26-36$ and $43 \mathrm{kDa}$, respectively), and they have been implicated in the regulation of pulmonary host defense and inflammation $[32,33]$. KL-6 is a high-molecular-weight $(>200 \mathrm{kDa})$ mucin-like glycoprotein which has been classified as human MUC1 mucin $[34,35]$. Serum/plasma SP-A, SP-D and KL-6 have been reported to represent sensitive markers for lung diseases, to the extent that in Japan they are used in clinical practice during the identification of idiopathic pulmonary fibrosis and other types of interstitial lung diseases. However, there are several problems in studies where SP-A has been evaluated from the circulating blood such as its elevation also in smokers, subjects with COPD or bronchiectasis and even in pulmonary thromboembolism [13-20]. It is likely that sputum samples that are derived directly from the lung would offer better insight, especially into the pathogenesis of chronic airway and/or other parenchymal lung diseases. A novel aspect ofthe present study 


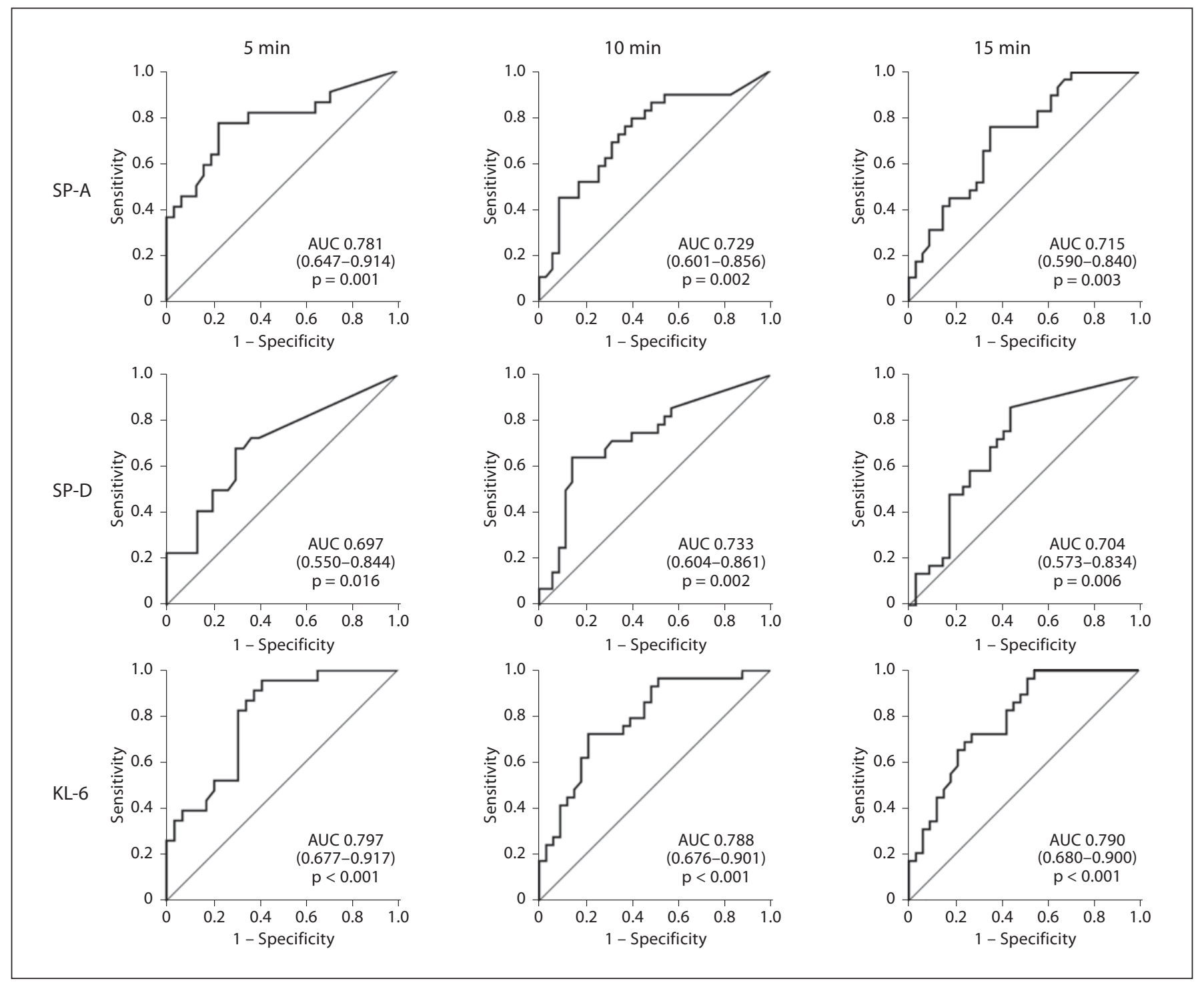

Fig. 2. ROC curves of SP-A, SP-D and KL-6 during induction (5-, 10- and 15-min samples) in subjects with COPD and prolonged cough. Values in parentheses indicate $95 \%$ confidence intervals for the AUC.

is that it represents a comparative study of SP-A, SP-D and KL-6 in induced sputum samples using sensitive and specific EIA/ELISA analysis for each marker.

It has been suggested that small-sized SP-A and/or SP-D leak more easily in parenchymal lung damage compared to the high-molecular-weight KL-6 so that more extensive enhancement of alveolar-capillary permeability is needed for the elevation of circulating KL-6 [36, 37]. Previous immunohistochemical analyses have revealed that SP-A and SP-D are prominently expressed in type II alveolar pneumocytes [38] and that KL-6 is expressed in type II alveolar pneumocytes and in bronchiolar epithe- lial and bronchial gland cells [39]. Other studies have detected SP-A also in the bronchiolar, tracheal, sinus and middle ear epithelium [17, 40-43]. This study indicates that sputum levels of SP-A, SP-D and KL-6 were elevated in the induced sputum of COPD patients compared to patients with prolonged cough. This may simply be due to the alveolar destruction, but it may also reflect the wide expression of these proteins in both the large and small airways of the diseased human lung. Since one typical feature in COPD is mucus production, more studies are needed to unravel the expression and cell-specific distribution of KL-6 in COPD and in its subphenotypes. 
Table 3. Correlations between the sputum levels of SP-A, SP-D and KL- 6 and the clinical parameters

\begin{tabular}{|c|c|c|c|c|c|c|c|c|c|}
\hline & \multicolumn{3}{|l|}{ SP-A } & \multicolumn{3}{|l|}{ SP-D } & \multicolumn{3}{|l|}{ KL-6 } \\
\hline & $5 \mathrm{~min}$ & $10 \mathrm{~min}$ & $15 \mathrm{~min}$ & $5 \mathrm{~min}$ & $10 \mathrm{~min}$ & $15 \mathrm{~min}$ & $5 \mathrm{~min}$ & $10 \mathrm{~min}$ & $15 \mathrm{~min}$ \\
\hline Age & $0.351^{*}$ & 0.167 & 0.145 & $0.374^{*}$ & $0.337^{*}$ & $0.351^{* *}$ & $0.575^{* * *}$ & $0.457^{* * *}$ & $0.459^{* * *}$ \\
\hline Pack-years & $0.324^{*}$ & 0.201 & 0.181 & 0.290 & 0.263 & 0.140 & $0.436^{* *}$ & $0.379^{* *}$ & $0.372^{* *}$ \\
\hline FVC & 0.096 & -0.056 & 0.131 & -0.026 & -0.075 & 0.015 & 0.040 & -0.111 & 0.072 \\
\hline $\mathrm{FEV}_{1}$ & -0.046 & $-0.268^{*}$ & -0.073 & -0.046 & $-0.269^{*}$ & -0.119 & -0.146 & $-0.332^{*}$ & -0.134 \\
\hline $\mathrm{FEV}_{1} \%$ predicted & -0.040 & $-0.360^{* *}$ & -0.091 & 0.064 & $-0.281^{*}$ & 0.004 & -0.061 & $-0.344^{*}$ & -0.081 \\
\hline $\mathrm{FEV}_{1}$ to $\mathrm{FVC}$ ratio & $-0.392^{* *}$ & $-0.324^{*}$ & $-0.308^{*}$ & -0.276 & $-0.343^{* *}$ & -0.219 & $-0.450^{* *}$ & $-0.394^{* *}$ & $-0.349^{* *}$ \\
\hline
\end{tabular}

${ }^{*} \mathrm{p}<0.05,{ }^{* *} \mathrm{p}<0.01,{ }^{* * *} \mathrm{p}<0.001$ (correlation between variables, by Spearman's rank correlation coefficient).

Table 4. Correlations between the sputum levels of SP-A, SP-D and KL-6 and sputum cell counts

\begin{tabular}{|c|c|c|c|c|c|c|c|c|c|}
\hline & \multicolumn{3}{|l|}{ SP-A } & \multicolumn{3}{|l|}{ SP-D } & \multicolumn{3}{|l|}{ KL-6 } \\
\hline & $5 \mathrm{~min}$ & $10 \mathrm{~min}$ & $15 \min$ & $5 \mathrm{~min}$ & $10 \mathrm{~min}$ & $15 \min$ & $5 \mathrm{~min}$ & $10 \mathrm{~min}$ & $15 \mathrm{~min}$ \\
\hline Sputum neutrophils (\%) & -0.227 & -0.104 & -0.135 & $-0.370^{*}$ & -0.117 & -0.187 & $-0.368^{*}$ & -0.190 & $-0.328^{*}$ \\
\hline Sputum macrophages (\%) & $0.438^{* *}$ & 0.228 & 0.225 & $0.474^{* *}$ & 0.057 & 0.180 & $0.531^{* *}$ & $0.278^{*}$ & $0.318^{*}$ \\
\hline Sputum lymphocytes (\%) & -0.157 & 0.174 & -0.095 & -0.212 & 0.039 & -0.097 & -0.173 & 0.064 & -0.114 \\
\hline Sputum eosinophils (\%) & 0.160 & -0.006 & -0.014 & $0.336^{*}$ & $0.343^{*}$ & 0.170 & $0.346^{*}$ & 0.199 & 0.198 \\
\hline Sputum neutrophils $\left(\times 10^{5} / \mathrm{g}\right)$ & 0.282 & 0.129 & 0.247 & 0.243 & 0.049 & 0.131 & 0.141 & 0.123 & 0.184 \\
\hline Sputum macrophages $\left(\times 10^{5} / \mathrm{g}\right)$ & $0.480^{* *}$ & $0.310^{*}$ & $0.367^{* *}$ & $0.477^{* *}$ & 0.172 & $0.329^{*}$ & $0.481^{* *}$ & $0.384^{* *}$ & $0.479^{* *}$ \\
\hline Sputum lymphocytes $\left(\times 10^{5} / \mathrm{g}\right)$ & 0.038 & 0.209 & 0.020 & -0.048 & 0.018 & 0.021 & -0.047 & 0.123 & 0.074 \\
\hline Sputum eosinophils $\left(\times 10^{5} / \mathrm{g}\right)$ & 0.249 & 0.029 & 0.060 & $0.469^{* *}$ & $0.330^{*}$ & 0.221 & $0.453^{* *}$ & 0.242 & 0.261 \\
\hline
\end{tabular}

${ }^{*} \mathrm{p}<0.05,{ }^{* *} \mathrm{p}<0.01$ (correlation between variables, by Spearman's rank correlation coefficient).

One major goal of the present study was to evaluate whether sputum fractionation itself has any major effects on the levels of these proteins. In this study, the percentage of neutrophils was higher in the early fraction than in the later fraction, whereas the percentage of macrophages increased towards the end of the induction. These results are in agreement with those of several previous investigations [9-12] and suggest that different parts of the respiratory tract are sampled into different fractions during induction. There is also evidence that induced sputum better reflects the central rather than the lower and peripheral airways [44-46]. One study on 12 subjects with mild and moderate asthma revealed that sputum levels of mucin-like glycoprotein are higher in the early fraction than in the later fraction, whereas sputum levels of SP-A appeared to be higher in the later fractions [11]. In agreement with these results, sputum SP-A levels in our subjects with prolonged cough showed an increasing trend towards the end of the sputum induction. Overall, sputum levels of all these proteins in each fraction resulted in a very similar ROC curve for the differentiation of the patients with COPD from the subjects with prolonged cough.

Although promising results were obtained, this study has limitations. One limitation is the low number of patients and thus the poor statistical power. The subjects with COPD were older than those with prolonged cough. The levels of sputum SP-A, SP-D and KL-6 increased with age, though the change was observed in both nonsmokers and smokers. More males had been included in the COPD group and more females in the prolonged cough group; there was also a significant difference between males and females, especially with regard to sputum levels of KL-6. The levels of SP-A, SP-D and KL-6 in the induced sputum supernatants of COPD patients were higher than in those of the prolonged cough patients in both nonsmokers and smokers. However, it is possible that smoking alone can increase these markers in sputum through an acute stress reaction or due to the minimal lung injury. There was also 
individual variability in the sputum levels of these proteins, which may be related to multiple reasons, from sputum production in general to dithiothreitol treatment, which in turn can interfere with immunoassays by reducing the antigen-antibody binding reaction. Certain technical factors, including the duration of the inhalation procedure and the concentration of saline solution, might have influenced the procedure, but previous studies have indicated that different saline concentrations do not significantly affect total cell count and differential cell counts [47] and that shorter inhalation times (e.g. 15-20 min) appear to have similar success rates and feasibility to the longer inhalation times $(30 \mathrm{~min})$ [27]. Since saliva generally contains much lower levels of mucins [48], possible contamination with saliva may have contributed to the final results obtained. In spite of these limitations, the main results of our study were straightforward and significant. However, more studies will be required in age-, sex- and smoking-history-matched subjects with various airway diseases compared to smoking and nonsmoking controls.

Even though induced sputum is relatively reproducible in COPD $[49,50]$, a large and prospective study, including also non-Asian subjects, will be required to evaluate the utility of sputum levels of SP-A, SP-D and KL-6 in COPD. The validation and definition of the specificity of these proteins in various chronic airway diseases will require further studies, especially in various phenotypes of COPD (airway vs. emphysema predominance) [22], allergic asthma, intrinsic-type asthma and asthma in smokers. A prospective follow-up of this nature is currently ongoing in a non-Asian (Finnish) cohort which contains unselected patients with asthma and COPD [51].

\section{Conclusion}

Sequential sputum analysis of induced sputum from 3 consecutive fractions demonstrated a significant difference between subjects with COPD and prolonged cough with regard to the sputum levels of SP-A, SP-D and KL-6. Sputum fractionation had a relatively minor effect on the levels of these proteins.

\section{Financial Disclosure and Conflicts of Interest}

This work was supported by Grants-in-Aid for Scientific Research from the Ministry of Education, Culture, Sports, Science and Technology of Japan. V.L.K. was supported in part by the Finnish Antituberculosis Association Foundation, a special governmental subsidy for health sciences research (HUCH-EVO) and by the Research Program for the Intelligent Monitoring of Health and Well-Being (Tekes).

\section{References}

-1 Rytilä P, Rehn T, Ilumets H, Rouhos A, Sovijärvi A, Myllärniemi M, Kinnula VL: Increased oxidative stress in asymptomatic current chronic smokers and GOLD Stage 0 COPD. Respir Res 2006;7:69.

-2 Kinnula VL, Ilumets H, Myllärniemi M, Sovijärvi A, Rytilä P: 8-Isoprostane as a marker of oxidative stress in nonsymptomatic cigarette smokers and COPD. Eur Respir J 2007; 29:51-55.

-3 Mazur W, Stark H, Sovijärvi A, Myllärniemi M, Kinnula VL: Comparison of 8-isoprostane and interleukin- 8 in induced sputum and exhaled breath condensate from asymptomatic and symptomatic smokers. Respiration 2009;78:209-216.

-4 Barnes PJ, Chowdhury B, Kharitonov SA Magnussen H, Page CP, Postma D, Saetta M: Pulmonary biomarkers in chronic obstructive pulmonary disease. Am J Respir Crit Care Med 2006;174:6-14.

5 Louhelainen N, Myllärniemi M, Rahman I, Kinnula VL: Airway biomarkers of the oxidant burden in asthma and chronic obstructive pulmonary disease: current and future perspectives. Int J Chron Obstruct Pulmon Dis 2008;3:585-603.
6 Kinnula VL, Ishikawa N, Bergmann U, Ohlmeier S: Proteomic approaches for studying human parenchymal lung diseases. Expert Rev Proteomics 2009;6:619-629.

7 Nicholas BL, O'Connor CD, Djukanovic R: From proteomics to prescription - the search for COPD biomarkers. COPD 2009;6:298303.

8 Montuschi P, Macagno F, Parente P, Valente S, Lauriola L, Ciappi G, Kharitonov SA, Barnes PJ, Ciabattoni G: Effects of cyclo-oxygenase inhibition on exhaled eicosanoids in patients with COPD. Thorax 2005;60:827-833.

-9 Holz O, Jörres RA, Koschyk S, Speckin P, Welker L, Magnussen $\mathrm{H}$ : Changes in sputum composition during sputum induction in healthy and asthmatic subjects. Clin Exp Allergy 1998;28:284-292.

10 Richter K, Holz O, Jörres RA, Mücke M, Magnussen H: Sequentially induced sputum in patients with asthma or chronic obstructive pulmonary disease. Eur Respir J 1999;14: 697-701.

11 Gershman NH, Liu H, Wong HH, Liu JT, Fahy JV: Fractional analysis of sequential in duced sputum samples during sputum induction: evidence that different lung com- partments are sampled at different time points. J Allergy Clin Immunol 1999;104: 322-328.

-12 Toungoussova O, Migliori GB, Foschino Barbaro MP, Esposito LM, Dragonieri S, Carpagnano GE, Salerno FG, Neri M, Spanevello A: Changes in sputum composition during $15 \mathrm{~min}$ of sputum induction in healthy subjects and patients with asthma and chronic obstructive pulmonary disease. Respir Med 2007;101:1543-1548.

13 Ohnishi H, Yokoyama A, Kondo K, Hamada H, Abe M, Nishimura K, Hiwada K, Kohno $\mathrm{N}$ : Comparative study of KL-6, surfactant protein-A, surfactant protein-D, and monocyte chemoattractant protein-1 as serum markers for interstitial lung diseases. Am J Respir Crit Care Med 2002;165:378-381.

14 Kobayashi H, Kanoh S, Motoyoshi K: Serum surfactant protein-A, but not surfactant protein-D or KL-6, can predict preclinical lung damage induced by smoking. Biomarkers 2008;13:385-392.

15 Honda Y, Takahashi H, Kuroki Y, Akino T, Abe S: Decreased contents of surfactant proteins A and D in BAL fluids of healthy smokers. Chest 1996;109:1006-1009. 
-16 Betsuyaku T, Kuroki Y, Nagai K, Nasuhara Y, Nishimura M: Effects of ageing and smoking on SP-A and SP-D levels in bronchoalveolar lavage fluid. Eur Respir J 2004;24:964-970.

-17 Ohlmeier S, Vuolanto M, Toljamo T, Vuopala K, Salmenkivi K, Myllärniemi M, Kinnula VL: Proteomics of human lung tissue identifies surfactant protein $\mathrm{A}$ as a marker of chronic obstructive pulmonary disease. J Proteome Res 2008;7:5125-5132.

$\checkmark 18$ Sin DD, Leung R, Gan WQ, Man SP: Circulating surfactant protein $\mathrm{D}$ as a potential lung-specific biomarker of health outcomes in COPD: a pilot study. BMC Pulm Med 2007;7:13.

$\checkmark 19$ Sin DD, Pahlavan PS, Man SF: Surfactant protein D: a lung specific biomarker in COPD? Ther Adv Respir Dis 2008;2:65-74.

20 Lomas DA, Silverman EK, Edwards LD, Locantore NW, Miller BE, Horstman DH, TalSinger R; Evaluation of COPD Longitudinally to Identify Predictive Surrogate Endpoints study investigators: Serum surfactant protein $\mathrm{D}$ is steroid sensitive and associated with exacerbations of COPD. Eur Respir J 2009; 34:95-102.

21 National Institutes of Health, National Heart, Lung and Blood Institute: Global initiative for the diagnosis, management, and prevention of chronic obstructive pulmonary disease, updated December 2009. www.goldcopd.com.

22 Rabe KF, Hurd S, Anzueto A, Barnes PJ, Buist SA, Calverley P, Fukuchi Y, Jenkins C, Rodriguez-Roisin R, van Weel C, Zielinski J; Global Initiative for Chronic Obstructive Lung Disease: Global strategy for the diagnosis, management, and prevention of chronic obstructive pulmonary disease: GOLD executive summary. Am J Respir Crit Care Med 2007;176:532-555.

23 Committee for the Japanese Respiratory Society Guidelines for Management of Cough, Kohno S, Ishida T, Uchida Y, Kishimoto H, Sasaki H, Shioya T, Tokuyama K, Niimi A, Nishi K, Fujimura M, Matsuse H, Suzaki H: The Japanese Respiratory Society guidelines for management of cough. Respirology 2006; 11:S135-S186.

24 Iwamoto H, Yokoyama A, Kitahara Y, Ishikawa N, Haruta Y, Yamane K, Hattori N, Hara H, Kohno N: Airflow limitation in smokers is associated with subclinical atherosclerosis. Am J Respir Crit Care Med 2009;179:35-40.

-25 Yamane T, Hattori N, Kitahara Y, Haruta Y, Sasaki H, Yokoyama A, Kohno N: Productive cough is an independent risk factor for the development of COPD in former smokers. Respirology 2010;15:313-318.

-26 Standardization of Spirometry, 1994 Update. American Thoracic Society. Am J Respir Crit Care Med 1995;152:1107-1136.
Paggiaro PL, Chanez P, Holz O, Ind PW, Djukanović R, Maestrelli P, Sterk PJ: Sputum induction. Eur Respir J Suppl 2002;37:3s-8s.

28 Kanehara M, Yokoyama A, Tomoda Y, Shiota $\mathrm{N}$, Iwamoto $\mathrm{H}$, Ishikawa N, Taooka $\mathrm{Y}, \mathrm{Ha}-$ ruta Y, Hattori N, Kohno N: Anti-inflammatory effects and clinical efficacy of theophylline and tulobuterol in mild-to-moderate chronic obstructive pulmonary disease. Pulm Pharmacol Ther 2008;21:874-878.

29 Bacci E, Cianchetti S, Ruocco L, Bartoli ML, Carnevali S, Dente FL, Di Franco A, Giannini D, Macchioni P, Vagaggini B, Morelli MC, Paggiaro PL: Comparison between eosinophilic markers in induced sputum and blood in asthmatic patients. Clin Exp Allergy 1998; 28:1237-1243.

-30 Pin I, Gibson PG, Kolendowicz R, GirgisGabardo A, Denburg JA, Hargreave FE, Dolovich J: Use of induced sputum cell counts to investigate airway inflammation in asthma. Thorax 1992;47:25-29.

-31 Ishikawa N, Hattori N, Yokoyama A, Tanaka S, Nishino R, Yoshioka K, Ohshimo S, Fujitaka $\mathrm{K}$, Ohnishi $\mathrm{H}$, Hamada $\mathrm{H}$, Arihiro K, Kohno N: Usefulness of monitoring the circulating Krebs von den Lungen- 6 levels to predict the clinical outcome of patients with advanced nonsmall cell lung cancer treated with epidermal growth factor receptor tyrosine kinase inhibitors. Int J Cancer 2008;122: 2612-2620.

32 Takahashi H, Sano H, Chiba H, Kuroki Y: Pulmonary surfactant proteins A and D: innate immune functions and biomarkers for lung diseases. Curr Pharm Des 2006;12:589598.

33 Kuroki Y, Takahashi M, Nishitani C: Pulmonary collectins in innate immunity of the lung. Cell Microbiol 2007;9:1871-1879.

-34 Hirasawa Y, Kohno N, Yokoyama A, Inoue Y, Abe M, Hiwada K: KL-6, a human MUC1 mucin, is chemotactic for human fibroblasts. Am J Respir Cell Mol Biol 1997;17:501-507.

35 Ohyabu N, Hinou H, Matsushita T, Izumi R, Shimizu H, Kawamoto K, Numata Y, Togame $\mathrm{H}$, Takemoto $\mathrm{H}$, Kondo $\mathrm{H}$, Nishimura S: An essential epitope of anti-MUC1 monoclonal antibody KL- 6 revealed by focused glycopeptide library. J Am Chem Soc 2009; 131:17102-17109.

36 Wright JR: Immunoregulatory functions of surfactant proteins. Nat Rev Immunol 2005; 5:58-68.

37 Inoue Y, Barker E, Daniloff E, Kohno N, Hiwada K, Newman LS: Pulmonary epithelial cell injury and alveolar-capillary permeability in berylliosis. Am J Respir Crit Care Med 1997;156:109-115.

38 Hermans C, Bernard A: Lung epitheliumspecific proteins: characteristics and potential applications as markers. Am J Respir Crit Care Med 1999;159:646-678.
9 Kohno N, Akiyama M, Kyoizumi S, Hakoda M, Kobuke K, Yamakido M, Hirasawa Y: Detection of soluble tumor-associated antigens in sera and effusions using novel monoclonal antibodies, KL-3 and KL-6, against lung adenocarcinoma. Jpn J Clin Oncol 1988;18: 203-216.

40 Woodworth BA, Lathers D, Neal JG, Skinner M, Richardson M, Young MR, Schlosser RJ: Immunolocalization of surfactant protein $\mathrm{A}$ and $\mathrm{D}$ in sinonasal mucosa. Am J Rhinol 2006;20:461-465.

41 Schlosser RJ: Surfactant and its role in chronic sinusitis. Ann Otol Rhinol Laryngol Suppl 2006;196:40-44.

42 Madsen J, Tornoe I, Nielsen O, Koch C, Steinhilber W, Holmskov U: Expression and localization of lung surfactant protein A in human tissues. Am J Respir Cell Mol Biol 2003;29:591-597.

43 Dutton JM, Goss K, Khubchandani KR, Shah CD, Smith RJ, Snyder JM: Surfactant protein $\mathrm{A}$ in rabbit sinus and middle ear mucosa. Ann Otol Rhinol Laryngol 1999;108: 915-924.

44 Alexis NE, Hu SC, Zeman K, Alter T, Bennett WD: Induced sputum derives from the central airways: confirmation using a radiolabeled aerosol bolus delivery technique. Am J Respir Crit Care Med 2001;164:1964-1970.

45 Rutgers SR, Timens W, Kaufmann HF, van der Mark TW, Koëter GH, Postma DS: Comparison of induced sputum with bronchial wash, bronchoalveolar lavage and bronchial biopsies in COPD. Eur Respir J 2000;15:109115.

-46 Keatings VM, Evans DJ, O’Connor BJ, Barnes PJ: Cellular profiles in asthmatic airways: a comparison of induced sputum, bronchial washings, and bronchoalveolar lavage fluid. Thorax 1997;52:372-374.

47 Popov TA, Pizzichini MM, Pizzichini E, Kolendowicz R, Punthakee Z, Dolovich J, Hargreave FE: Some technical factors influencing the induction of sputum for cell analysis. Eur Respir J 1995;8:559-565.

48 Nicholas B, Djukanović R: Induced sputum: a window to lung pathology. Biochem Soc Trans 2009;37:868-872.

49 Beeh KM, Beier J, Kornmann O, Mander A, Buhl R: Long-term repeatability of induced sputum cells and inflammatory markers in stable, moderately severe COPD. Chest 2003; 123:778-783.

50 Brightling CE, Monterio W, Green RH, Parker D, Morgan MD, Wardlaw AJ, Pavord D: Induced sputum and other outcome measures in chronic obstructive pulmonary disease: safety and repeatability. Respir Med 2001;95:999-1002.

51 Laitinen T, Hodgson U, Kupiainen H, Tammilehto L, Haahtela $T$, Kilpeläinen $M$, Lindqvist A, Kinnula VL: Real-world clinical data identifies gender-related profiles in chronic obstructive pulmonary disease. COPD 2009;6:256-262. 